\title{
An Effective Industry Institute Engagement for Curriculum Design and Delivery: A Success Story
}

\author{
Ashok Shettar ${ }^{1}$, B.L.Desai ${ }^{2}$, Nalini C. Iyer ${ }^{3}$, Uma K. $\mathbf{M}^{4}$, A.B.Raju ${ }^{4}$, C.D.Kerur ${ }^{5}$,P.C.Nissimagoudar ${ }^{6}$, \\ Venkatesh Mane ${ }^{7}$, Ramakrishna $S^{8}$, Kiran M.R ${ }^{9}$, Sanjay Eligar ${ }^{10}$, Anil Badiger ${ }^{11}$, and Anisha Joseph ${ }^{12}$ \\ B.V. Bhoomaraddi College of Engineering and Technology, Hubli,India
}

\begin{abstract}
This paper presents details of an industry institute engagement evolved for effectively bridging the gaps \& creating readily deployable manpower with the requisite talent and skill set for the automotive industry. The success story presented brings out the details of conceptualization, curriculum design and course delivery model for an interdisciplinary course on automotive electronics at the under graduate engineering program in electrical sciences. Issues of very strong involvement of the industry at different levels of the engagement, including the commitment of the top Management from both sides, and the dedication of the teams involved are discussed. How the faculty from the electronics background have worked together with the faculty from the automobile background to make this successful are brought out. The significant outcomes of this initiative in terms of learning takeaways, improvement in job readiness of the graduates and influence on research initiatives in various relevant domains are presented.
\end{abstract}

Keywords - Industry-institute interaction, automotive electronics, course design, industryspecific skills.

Ashok Shettar

B.V. Bhoomaraddi College of Engineering and Technology, Hubli, India

\section{Introduction}

The journey of cooperation between institute and industry has taken different forms at different times. Earlier, it started with simple interaction and gradually evolved to very close partnership overtime. There is very little linkage between what is taught in academic institutions and what is required in actual field of employment. We need to build an implicative system to bridge the skill gap and to sustain in the changing scenario; hence there is great need of an efficient Institution Industry Interface[1][7].

This paper brings out the success story of the institute-industry interaction mainly to fill the gap between the two. Here we focus on the course Automotive Electronics offered to cater the above mentioned issue. The paper discusses about the involvement of various automotive and embedded industries at different levels of course design and execution and also reflects on the outcomes of the activity. There is a high demand for qualified individuals in the automotive service field. The desire for the students to obtain industry-based training at the under graduate level and step up to the higher level of competency in this field is the eventual goal of this course. The involvement of industry at different levels has enhanced the learning of the students along with developing industry specific skills. 
The course delivery methods practiced were also contributing towards better learning of the course and making them industry ready. By this we are trying to expose the students to the world of emerging technology and making them industry relevant.

The major objective to initiate institute-industry interaction at BVBCET, Hubli in association with Robert Bosch Business and Engineering solutions India (RBEI) and KPIT Ltd, is to provide the platform for showcasing latest technological advancements, their implementation and to develop the industry specific skills among the students. It is basically considered to improve the quality of technical education adequately to meet the needs of the industry and economy. Having a close interaction in place, industries are able to participate in technical education programs, with the goal of cross-fertilizing ideas for systems improvement. The academic autonomy status of the institute facilitates establishment of collaborative relationship with the industry through Memorandum of Understanding (MoU).

Faculty training and other inputs from the industry has helped in designing the curriculum and also enhanced the teaching learning processes. This interaction is necessary as it develops students', awareness on job function in the industry, attitudes to adapt to industrial environment, proper practical and relevant knowledge, skills and competencies in preparation to become employed. Industry expectations are also echoed through sound interaction, particularly the requirements from new recruits who are expected to be orientated to industrial disciplines.

The course along with the delivery and evaluation methods addresses both the technical and professional outcomes of the program. The involvements of industrial inputs were observed at all the levels of course design and delivery.

Organization of the paper is as follows section II deals with Establishment industry-institute engagement section III with Industry driven course design, section IV deals with Involving industry and its inputs to deliver the course, section IV deals with Impact of industry-institute engagement to the course and section VI with Conclusion.

\section{Institute-Industry Collaborative Engagements}

According to the survey it is observed that $75 \%$ of the Indian engineering students not fit for employment immediately after their graduation. They lack in skills required by the industry. The industries usually need to spend initial period of their employees on developing those skills. There is always a requirement of qualified employees and industries will be interested in reducing their training period. It is observed that generally both industries and engineering institutions function independently. But, always there is a requirement that both need to move closer to create synergies[2]. The theoretical strength of the institutions and the practical experience of the industry will be synergized when they join hands. A productive interface between academia and industry is a critical requirement for the development of any nation in this era of knowledge economy.

The automotive industry is today the sixth largest economy in the world, producing around 70 million cars every year and making an important contribution to government revenues all around the world [3][8]. The automotive industry is multidisciplinary in nature; it requires the engineers from diverse streams like mechanical, computers and electronics. The placement opportunities are also very vast across the various disciplines of engineering. With these things in background it is found that introducing automotive electronics and related courses will enhance the carrier opportunities of the student. The industry involvement in design and delivery of these courses will be an added advantage.

The BVB College of engineering and technology

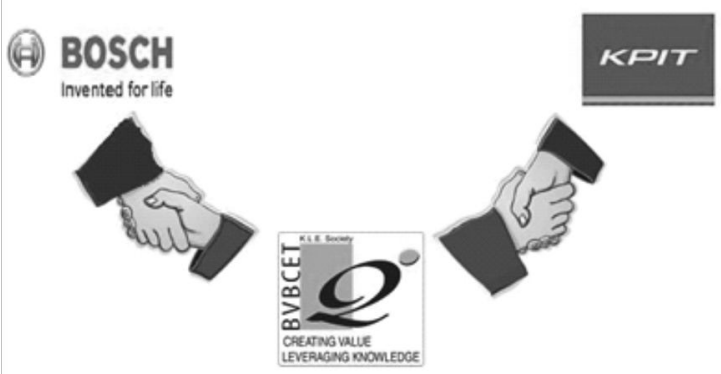

Fig 1. BVB collaboration with RBEI and KPIT

has found that the RBEI and KPIT are the two main leading automotive industries who can contribute to institutes. The industry- institute engagement was initiated by signing the Memorandum of Understanding (MOU)s with these industries as depicted in Fig. 1. Even though both these industries are competitors but they are collaborators to us. The 
are competitors but they are collaborators to us. The objectives of this collaboration are,

- To design more relevant curriculum

- To upgrade the competency of the faculty

- To provide internship to students

- To provide more opportunities for placement

- To strengthen practical skills of both faculty and students

- To upgrade the student and faculty with current technologies

- To provide industry ready employees to industry

- To conduct industry specific research at institute

- To reduce recruitment cost for industries

- To conduct collaborative research

The collaboration requires the industries to participate in design of course, participate in Board of studies (BOS) of the institute, provide technical training to the faculty, conduct expert lecture to students, provide internship to students, sponsor industry specific hardware, software and tools to institute. The institutes in turn provide the industries the more qualified graduates with industry specific skills, the institutes to conduct research specific to industrial projects. Both the industries and institutes are equally benefitted by this collaboration.

\section{Industry Driven Curriculum Design}

Curriculum is defined as the scientific study of academic programs starting from a need analysis to the design of effective graduate profiles, program/course objectives, content, sequencing, methodologies and learning assessment. A welldesigned course gives educational processes a scientific foundation that would allow for efficiency and effectiveness in the workplace and industry within a specific social, political, economic and cultural context[4]. Course becomes the strategic platform within this framework to achieve objectives focused on planning, forecasting and control, responding to the needs of the industrialized and modernized world.

Its design and operationalization was possible because of the collaborative efforts by BVBCET,Hubli , Karnataka , RBEI, Banglore, Karnataka and KPIT,Pune. Maharastra. The curriculum was designed in such a way that it integrates with the mission and learning objectives of the department along with the academic strategic plan and the pedagogical model of the institution.

The main purpose of designing and introducing the Automotive Electronics into the curriculum was basically to meet challenges in the contemporary industries and to make the students sustainable to work in any environment.

The course design teams mainly consisted of the industrial expertise from RBEI and KPIT , top management from the BVBCET and also the eminent faculties from the departments of Electronics \& Communication Engineering, Instrumentation Technology, Electrical \& Electronics Engineering and Automobile Engineering. The inputs for designing the curriculum have been done even considering the societal requirements as depicted in Fig. 2. The members of the committee have pedagogical and complex systems knowledge for being the paradigm on which the model is structured.

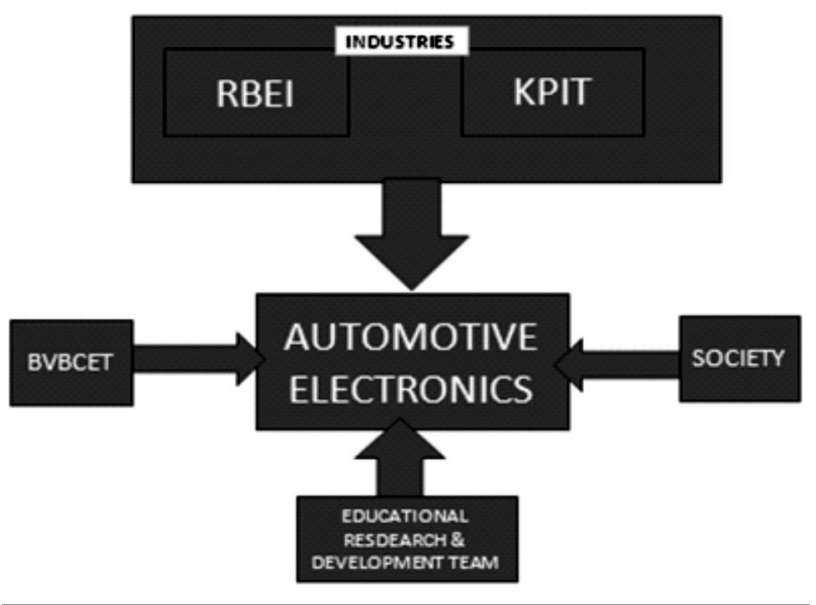

Fig 2. Industry driven Curriculum design

The Automotive Electronics course is a three credit one which has been introduced for the sixth semester students of Electrical science streams of our institute. The course has been designed with the following course out comes,

1. To provide a comprehensive overview about the existing and future automotive electronic systems.

2. To illustrate the distinctive features of the automotive world in terms of requirements and technologies.

3. To demonstrate the role of electronics for the areas 
like In-vehicle architectures, networking, engine management systems, vehicle safety systems \& infotainment systems.

4. Analyze the current status of software in the automotive industry and present the specifications elaborated within the AUTOSAR consortium in terms of standardization.

5. Design and implement a generic automotive system using appropriate platform.

The mapping of the course outcomes with the program outcomes of ABET are shown in the Table I. Both the technical (a, c ,d) and professional (g, i, j,k) outcomes are achieved through the course.

Table 1. Mapping of Course Outcomes with ABET 3A to $3 K$

\begin{tabular}{|c|c|c|c|c|c|c|c|c|c|c|c|}
\hline & a & b & c & d & e & f & $\mathrm{g}$ & h & $\mathbf{i}$ & $j$ & $\mathbf{k}$ \\
\hline & 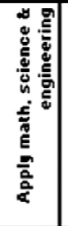 & 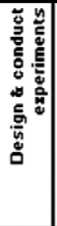 & 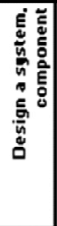 & 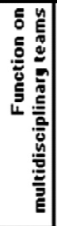 & 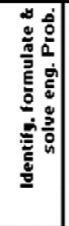 & 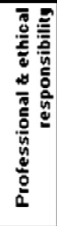 & 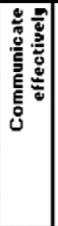 & 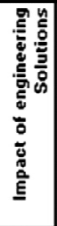 & 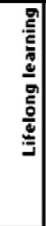 & 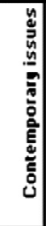 & 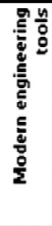 \\
\hline 1 & $M$ & & & . & & & & & & & \\
\hline 2 & $M$ & & & & & & & & & & \\
\hline 3 & $M$ & & & & & & & & & & \\
\hline 4] & $M$ & & & & & & & & & & \\
\hline 5 & $M$ & & $M$ & $\mathrm{~L}$ & & & $M$ & & L & L & $\mathrm{L}$ \\
\hline
\end{tabular}

The course mainly focuses on the study of electromechanical systems in-order to make them acquainted with the new applications that are being developed for future automobiles. There is balanced blend of electronics and mechanical concepts are being introduced to the students through this course. There is a unit wise split up for this course where in different units showcases on different areas of automobile systems. Unit I deals with basics of mechanical systems and the need for electronics in automobile systems. Unit II focuses on different Automotive Sensors, Actuators and their communications protocols. Unit III deals AUTOSAR, Advanced topics in safety systems and infotainment systems.

\section{Industry Contribution For Course Delivery}

The course like automotive electronics requires practicing additional pedagogical activities including conventional classroom teaching. The industry contribution in this connection helped to strengthen the course delivery Fig. 3 .

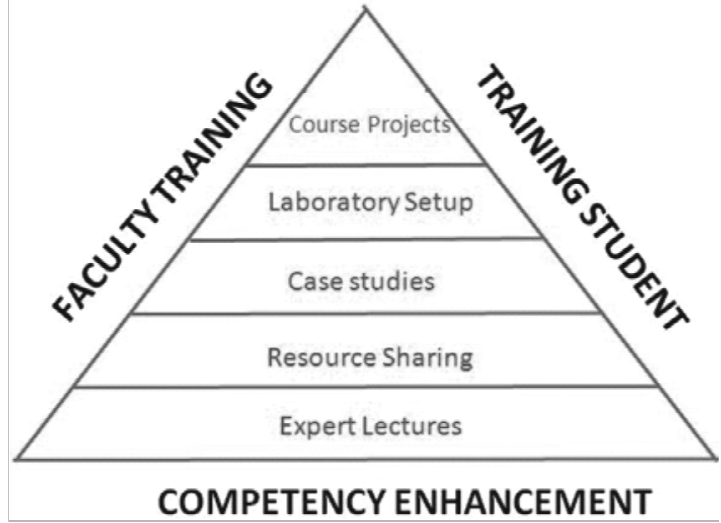

Fig 3. Industry contribution for course delivery

The industry contributions for course delivery are discussed below,

\section{A. Case studies on automotive electronics:}

The industries formulated the case studies relevant to the course and considering the latest development in the domain. These problem statements were given to the students as course projects. The students' participation in executing these course projects helped them to enhance their technical abilities. This activity has also resulted in building a strong knowledge of fundamentals, realizing the various aspects engineering analysis and hence the problem solving ability of the student enhanced.

\section{B. Expert lectures to the students:}

To make sure that the students get to know about the latest applications, technologies and requirements in automotive electronics expert lectures by industry like KPIT and RBEI were included in the curriculum. With this activity student can correlate the theoretical concepts learnt to applications of the industry. The gaps and scope for innovation can also be identified.

\section{Training for faculty:}

The faculties dealing with the course were trained exclusively by the industries. The training included both theory and hands on sessions. The training enhanced the technical competencies of the faculty.

\section{Technical Resources sharing:}

As the course is multidisciplinary and highly application oriented the technical recourses openly available are limited. The industries as a part of form 
collaboration share the recourses developed from them. These resources are in the form course material, videos, animations and technical presentations. These help in effective learning of the course.

\section{E. Laboratory set-up:}

As a part of collaboration with industries, a major contribution of industries was in the form of setting up of state of art laboratory. The RBEI has initiated BVBRobert Bosh automotive electronics laboratory at our campus.

The laboratory is equipped with a complete automotive electronics test and development environment ranging from the controllers, the core components to the power train systems. Electronic control unit (ECU) development platform works from the controller hardware design, software and operating system development, to control strategy Hardware in loop simulation(HIL)development, controller prototyping and various reliability tests, covering the entire process of the controller development.

Another major advantage of this lab initiation is the institute can conduct industry specific research and industry based projects can be executed.

\section{Impact Of Institute- Industry Engagement}

Close interaction between the institute and the industry is seen as the platform for showcasing best practices, latest technological advancements and their implementation and impact on the Industry[5]. It is basically considered to improve the quality of technical and vocational education adequately to meet the needs of the industry and economy. Mutual benefit is derived from the shared expertise and experiences between the institute and the industry.

\section{A. Benefits for Iinstitutes:}

\section{A.1 Enhancement in student placements:}

The major outcome of this collaboration was in terms of student placement. There was a substantial increase in automotive companies visiting our campus. The collaborated companies viz. KPIT and RBEI have increased their intake of the number of students. KPIT visited our campus three times for recruitment of the same batch of students i.e. during 2013. The Fig 4 below shows the continuous improvement of placements of our students in

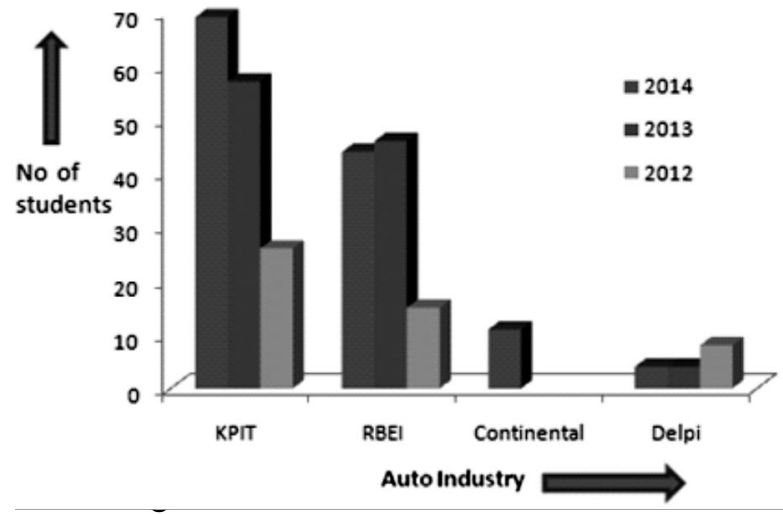

automotive industries for the past three years.

A.2 Internship to students:

Exploring is a very important part of the academic process, and gaining a work experience is a great way for students to acquaint themselves with a field they are looking to learn about [6]. Our both under graduate and post graduate students are given an advantage of experiencing industry environments and technical aspects through internship provided by these collaborated industries.

A.3 Enhancements in students' participation in technical project competitions:

The collaboration with industry has enhanced the technical competence of the students; the quality of projects students carried out was challenging and many innovative ideas were tried. Around 25 different projects with different themes were participated in different project competitions out of which eight teams have won the top prizes.

A.4 Enhancement in students' industry based projects:

The industrial internship and industry based problems provided by the collaborative industries has resulted in students solving these problems through their mini and major projects. So the quality of overall students' projects has improved. With this students placement in core industries and the opportunities for higher studies in reputed organizations has enhanced.

A.5 Faculty initiating industry specific research:

There were lots of opportunities in industry based research in the collaborated industries. The faculty of the institute got exposure to those opportunities and they initiated an industry based research. The advantage also was in terms resource sharing.

A. Benefits for industries:

B.1 Industry ready qualified employees:

Recruiting new team members who are already exposed to latest automotive technologies can cut down OJTs (On job trainings) considerably and makes them available on board as early as possible and 
becomes billable and can generate huge revenues. Since new team member is already on board development work can take faster pace. Projects deadline can be met well within time. This makes industries grow stronger and faster and take up new challenges and compete with global challenges.

\section{B. 2 Reduction in R\&D cost of industry:}

The collaboration lays a strong emphasis on the industry based research and product development. The industries contribution of setting up of laboratory at institutes and supporting infrastructure helps the students and faculty to take up R \& D projects of industry and hence reduces industries' investment on R\&D.

\section{Conclusion:}

At present both industry and institutes are working in highly competitive environment. It is important for academia and industries to get together to identify the types of skills that students need to work in real life. There should be synergy between institutes and industries. In this regard BVBCET Hubli, KPIT and RBEI are working collaboratively to minimize the gap between industry and academia. The efforts have resulted in enhancing the quality of education and enriching the skills and knowledge of students specific to automotive domain. The industry has also benefitted by this collaboration as they get industry ready employees.

\section{Acknowledgment}

The authors would like to acknowledge, the industry personnel from automotive industries KPIT Cummins and RBEI for their contribution in establishing the institute-industry collaborative engagements.

\section{References}

[1] Anju Sigroha, Anjali Chahal Industry- Institute Interaction: Searching New Horizons, International Journal of Techno-Management Research, Vol. 01, Issue 02, September 2013 ISSN: 2321-3744

[2] Petruzzelli, A. M.(2011) "The impact of technology relatedness, prior ties, and geographical distance on university-industry collaborations", Technovation, vol. 31, issue 7 ( pp. 309-319)

[3] Understanding automotive electronics, William B. Ribbens, Newnes,An Imprint of Elsevier ScienceElsevier Science (USA).

[4] Nangia V.K.,Pramanik C (2011) "Towards An Integrated Model for AcademiaIndustry Interface in India" Vol 49 World Academy of Science, Engineering and Technology (pp. 334341)

[5] Brodie, L.; Bullen, F.; Gibbings, P.(2011); "Developing an engineering education research culture," Global Engineering Education Conference (EDUCON), 2011 IEEE, (pp. 214219), 4-6April

[6] Paul Saibal (2010) “Industry Institute Interaction for Long Term Benefits" Features SME World http://www.smeworld.org/story/features/industr y-academia-interaction.php

[7] Majumdar, S. (2009). "Industry Institute Interaction to Public Private Partnership: A journey to excellence" CPSC 2009. Manila, Philippines 